South African Journal of Geomatics, Vol.6, No.3, October 2017

\title{
Large scale mapping: an empirical comparison of pixel-based and object-based classifications of remotely sensed data
}

\author{
Innocent E. Bello ${ }^{*}$, Njike Chigbu ${ }^{2}$, Ganiy I. Agbaje ${ }^{1}$ \\ ${ }^{1}$ National Space Research and Development Agency (NASRDA), PMB 437 Garki, FCT-Abuja, \\ Nigeria \\ *innobello@gmail.com \\ ${ }^{2}$ Dept. of Surveying \& Geoinformatics, Abia State Polytechnic, Aba, Abia State, Nigeria
}

DOI: http://dx.doi.org/10.4314/sajg.v6i3.1

\begin{abstract}
In the past, large scale mapping was carried using precise ground survey methods. Later, paradigm shift in data collection using medium to low resolution and, recently, high resolution images brought to bear the problem of accurate data analysis and fitness-for-purpose challenges. Using high resolution satellite images such as QuickBird and IKONOS are now preferred alternatives. This paper is aimed at comparing pixel-based (PIXBIA) and Geo-object-based (GEOBIA) classification methods using ENVI 4.8 and eCongnition software respectively, and ArcGIS 10.1 for map layout creation. It uses Aba main city in south-eastern Nigeria as a case study. The paper further evaluates the classification accuracies obtained using error matrix and then test the classifications' agreement to geographic reality using Kappa Coefficient statistical analysis. Analyzing 2012 QuickBird image as a proof of concept, the study shows that the objectbased approach had a higher overall accuracy $(O A=98.75 \%)$ than the pixel-based approach $(O A=79.44 \%)$. With a Kappa Coefficient of $K=0.97$ (very good) for object-based approach and $K=0.62$ (good) for pixel-based, the object-based method showed a higher class separability between and among examined geographic objects such as water, bare-land and tree canopy as evidenced in the Golf Course under re-construction in Aba city. In addition, the object-based results also show a higher overall producer accuracy $(P A=98.42 \%>P A=85.37)$ and user accuracy $(U A=96.70>U A=81.04 \%)$ respectively. The paper, therefore, recommends that objectbased classification method be applied in analyzing high resolution satellite image. The approach is also recommended for mapping urban areas in developing countries such as Nigeria where the paucity of fund required in flying airplane for the production of orthophotos is a major challenge in large scale mapping.
\end{abstract}

Keywords: Image Classification, Object-based Classification, Pixel-based Classification, Remote Sensing, Urban Planning and Mapping.

\section{Introduction}

Geospatial elements that vary aerially over earth's surface are almost limitless (Akinbode, 1996). However, the importance of accurate and up to date land cover and land use information is increasing (Verhulp and Niekerk, 2017). Consequently, studies using Remote Sensing data, 
Cartographic principles and Geographic Information System (GIS) in examining earth's surface spatial elements are specifically aimed at making informed decisions because the spatial outputs, mostly in the form of maps and accompanied statistics, help in resource allocation and landuse management on one hand, and policy impact analysis on the other hand (Goodchild, 1992; Ojigi, 2006; 2012). In addition, informed decisions are useful for planning purposes in areas like topographical mapping (Ikhuoria and Ogedegbe, 1998; Soneye and Akintuyi, 2013), environmental management (Worboys, 2003), land suitability and crop production (Verhulp and Niekerk, 2017; Rilwani, 2014), topographic analysis and visualization (Yokoyama, Shirasawa and Pike, 2002; Fabiyi, Ige-Olumide and Enaruvbe, 2012; Nkeki and Asikhia, 2014), as well as urbanisation, industrialization and regional planning (Omuta, 1984; Fasona and Omojola, 2004). In other words, having reliable and up-to-date spatial data sources such as Satellite Remote Sensing, ground surveying and croudsourced mapping are regarded as fundamental to effective planning and infrastructural development (Ufuah, 2003; Bello and Ojigi, 2013).

Previous studies showed that the dearth of reliable and up-to-date geographic data is a major drawback in making informed decisions as far as good governance and development are concerned in developing countries like Nigeria (Ufuah, 2003; Nkeki and Asikhia, 2014; Rilwani, Bello and Onothoja, 2015). Besides, the high temporal resolution in continuously providing multi-date satellite image data over a given geographic space is germane (Roostaei, Alavi, Nikjoo, and Valizadeh-Kamran, 2012). The Shuttle Radar Topography Mission (SRTM) and Advanced Spaceborne Thermal Emission and Reflection Radiometer (ASTER) datasets also provide data for timely production of topo-maps (McRoberts and Tomppo, 2007). There is usually the professional need to interpret and classify these datasets into information outputs such as maps. Since maps are beneficial for planning purposes, it is, therefore, very imperative that information contained in a map also reflect record of reality in space over time as accurately as possible (Ufuah, 2003).

Literature, however, shows that governments are less willing to foot the bill for national map making efforts (Goodchild, 2009). This has given room for amateurs' involvement in crowdsource mapping and Volunteered Geographic Information (VGI) (Bello and Ojigi, 2013). VGI is, however, not without fit-for-purpose data quality challenges (kraak and Ormeling, 2010). In literature, map making from aerial photos has been criticized for its time consumption, tedium, high cost and low accuracy (Collier, 2002; Ozah and Kufoniyi, 2008). This is because, prior to the introduction of GIS technology, cartographers relied heavily on data derived from conventional survey which also relied heavily on instruments such as ranging poles, Günter's chain, and tapes (Ikhuoria, 1998) to produce topographical maps that were largely interpolated with contour lines and manually produced hill shaded maps (Nkeki and Asikhia, 2014; Alpha and Winter, 1971; Imhof, 1965). With the advent of aerial photographs, most maps were produced photogrammetrically through mathematical measurements of features in the photos.

Conceptually, a map could be described as a scaled diagrammatical representation, simplification or model of any part of the earth surface on a projected plane or medium in 2D or 3D (Imhof, 2007; Chang, 2012; Osborne, 2013). Whether using ratio, representative fraction or statement scale 
(Kraak and Ormeling, 2010), maps may be generally divided into (a) small scale (1:20,000,000 and above - e.g. world map), medium scale (1:600,000 - 1:2,000,000 - e.g. country wide maps) or large scale (1:0 - 1:600,000 - e.g. town plan, cadastral and urban maps). In fact, regardless of the type of projection system used (Snyder, 1993), large scale mapping show small area with more details while small or medium scale mapping show larger areas with less details (Imhof, 2007; Olomo, 2007). Unfortunately, in most developing countries in Africa such as Nigeria, Ufuah (2003) argued that some of the aerial photographs used for the production of the Nigeria's scale 1:50,000 map series were acquired between 1956 and 1972 implying an age range between 31 to 47 years old. Yet, these maps still remains, more or less, the most authentically available base maps being used today in the country without visible updating in tandem with the United Nations Organisation's (UNO) recommended revision period of 10 years for areas of high human activities and 15 years for remote areas. This paucity is common with most African countries like Nigeria, where poverty and inadequacy in technological advancement in the area of geospatial information has resulted in the inability of such countries to regularly produce new topographical maps especially on a wider scale (Ozah and Kufoniyi, 2008). Consequently, there is now a shift from terrestrial survey and air photo to space-based satellite remote sensing for many applications such as urban planning and management (Myint et al., 2011) and topographic mapping (Ufuah, 2003).

Since 1972 when the first Earth Observation Satellite (EOS) was launched for environmental applications, the traditional method of mapping was first through analogue or visual analysis and later through the use of pixel-based method by classifying satellite image into landcover information classes (Ikhuoria, 1998). As a result of available low spatial resolution images characterised by coarseness and the salt-and-pepper-like short-comings, the pixel-based method could better be used for a generalized small scale mapping (large area with lesser details) especially in landcover change detection (Verhulp and Niekerk, 2017) and topographic mapping applications of a region (Matinfar et al., 2007; Roostaei et al., 2012). With the advent of high resolution satellite data such as IKONOS (1m), QuickBird (0.6m) and NigeriSat-2 (2.5m Pan \& 5m Multispectral) that are suitable for urban and cadastral large scale mapping, the development of robust ObjectOriented (object-based) classification method now provides a valid alternative to the 'traditional' pixel-based methods (Baatz, 2004; Benz, 2004; Whiteside and Ahmad, 2005). Importantly, maps generated from remotely-sensed data and other ancillary sources cuts across a number of sectorial usages (Olomo et al., 1998).

Due to rigours in the use of Global Positioning System (GPS) receivers in rapid mapping, the advent of remote sensing and orthorectified satellite image classifications has not only reduced drudgery but has also improved mapping accuracies. Conceptually, satellite image classification is the grouping, rendering, conversion or mapping of picture elements (PIXEL) with similar digital numbers representing a spatial feature as information class (Yu et al., 2006; Matinfar et al., 2007). The geographical reliability, relevance, usefulness and accuracies of acquired and analysed remotely sensed data is important for various applications and uses as this is the crux of differentiating and comparing the pixel-based and object-based classification methods. 
Previous studies on the above methods of classifications include those of Roostaei et al., (2012); Whiteside and Ahmand (2005); Matinfar et al., (2007); Flores et al., (2009); Myint et al. (2011); and Lu and Weng (2007). The trend and relevant studies on passive or active Remote Sensing using either pixel-based, object-based and or direct field survey with ancillary data for landuse/cover mapping, urban studies, environmental management and planning include the works of Erol and Akdenz (1998); Dymond and Shepherd (1999); Syed, Dare and Jones (2005); Matinfar et al., (2007); Rilwani (2014); and Yu, et al., (2006). Their findings indicate that a better approach to geospatial data analysis usually guarantees a reliable use of the derived products for informed decision making and planning.

This paper is, therefore, aimed at comparing object-based and pixel-based classification methods to urban mapping with empirical applications using part of Aba city in south-eastern Nigeria.

Theoretically, the pixel-based image classification (PIXBIA) technique is based on conventional computer-based statistical techniques, such as supervised and unsupervised classifications or both (Verhulp and Niekerk, 2017; Matifar et al., 2007). Supervised classification (semi-automatic) entails selecting training samples (Congalton and Green, 1999); performing classification using algorithms and assessing the accuracy of the classified image through the analysis of a confusion matrix that is generated either from random sampling or using test areas as reference data (Jensen and Gorte, 2001). Conversely, unsupervised classification requires no training data or sample classes. Pixels are assigned spectral classes based on their reflectance properties into "clusters".

According to Matinfar et al., (2007), considerable advancements have recently been made in the development of Geo-object-based image analysis (GEOBIA) method of satellite image classification as a result of perceived low accuracy and salt-and-pepper-like anomalies in the traditional pixel-based approach. The theory or principle behind the GEOBIA method is called the fuzzy theory. Based on this theory, objects (earth features) are classified into more than one class with different membership values (Benz et al., 2004). Hay et al., (2001) defined the objects in GEOBIA technique as "basic entities located within an image, where each pixel group is composed of similar digital values, and possesses an intrinsic size, shape, and geographic relationship with the real-world scene component it models". In object-based classification method, segmentation (feature grouping) generally uses membership to express an object's assignment to a landcover class. The membership value usually lies between 1.0 and 0.0 ; where 1.0 expresses a complete assignment to a class, and 0.0 expresses absolutely improbability (Matinfar et al., 2007). In addition, the techniques of image segmentation are grouped into three (Fu and Mui, 1981) viz: (1) thresholding/clustering, (2) region based, and (3) edge based; all of which together with classification depends on set parameters such as scale level, shape factor, smoothness and compactness (Gao and Mas, 2008). Practically, GEOBIA combines spectral, spatial, texture and context information in the process of classification. Operationally, the steps involved in objectbased classification are: (i) image segmentation, (ii) rule setting, (ii) training sample, and (iv) classification into information classes. 
It is important to examine the context under which regionalization and spatial proximity models are used in satellite image segmentation. This is because; satellite image segmentation may be explained using the regionalization model credited to Paul Vidal de la Blache (1845-1918). Based on this model, during image segmentation, images are divided based on certain criteria of homogeneity forming a feature region that requires spatial contingency and geographical proximity of unbroken contiguity (Gao and Mas, 2008). Explaining the application of the concept of regionalisation further, Tobler's first law of Geography (or principle of spatial auto-correlation) states that "everything is related to everything, but near things are more related than distant things" (Tobler, 1970). Although two major options of assigning classes in segmented objects are based on (i) membership function classifier, and (ii) nearest neighbour classifier - NNC (Myint et al., 2011), a large number of image segmentation algorithms are based on region growing methods. Following Tobler's first law of Geography, the segmentation approach always provides closed boundary of objects and makes use of relatively large neighbourhoods for decision making (Yu et al., 2006). Since the region growing approac is mostly adopted, it requires consideration of seed selection, growing criteria, and processing order. Some studies have developed hybrid methods in which edge or gradient information has been used in combination with region growing for image segmentation (Gambotto, 1993; Lemoigne and Tilton, 1995 in Yu et al., 2006). The level of membership now depends on the degree to which the objects fulfil the class-describing condition (Matinfar et al., 2007) based on set parameters (Whiteside and Ahmad, 2005).

In view of the above, this research uses an empirical case study of a typical urbanizing environment in comparatively assessing pixel-based (PIXBIA) and object-based (GEOBIA) remote sensing classification methods for large scale rapid mapping with a view to ascertaining the level of reliability in terms of their respective accuracies and fitness-for-use or fitness-for-purpose.

\section{Materials and Method}

\subsection{The Study Area}

Aba is a major trading city in the south-eastern part of Nigeria. The study area is geographically located within Latitudes $5^{0} 3^{\prime} 47^{\prime}$ ' $\mathrm{N}$ and $5^{0}$ 9' $16^{\prime}$ ' $\mathrm{N}$, and Longitudes $7^{0} 19^{\prime} 22^{\prime}$ 'E and $7^{0} 24^{\prime} 25^{\prime}$ ' E respectively as shown in Figure 1. Located on the Aba River, Aba City is made up of many villages with an average elevation of $205 \mathrm{~m}$ (673 ft). On the average, the study area has a temperature of $28^{\circ} \mathrm{C}$, Wind Speed of $8 \mathrm{~km} / \mathrm{h}$, and Humidity of $80 \%$. Though ethnically an Igbo speaking urban space, the geographical influx of people from different parts of the country as a result of socioeconomic (mostly trade) and political factors has made Aba a city with different ethnic population. 


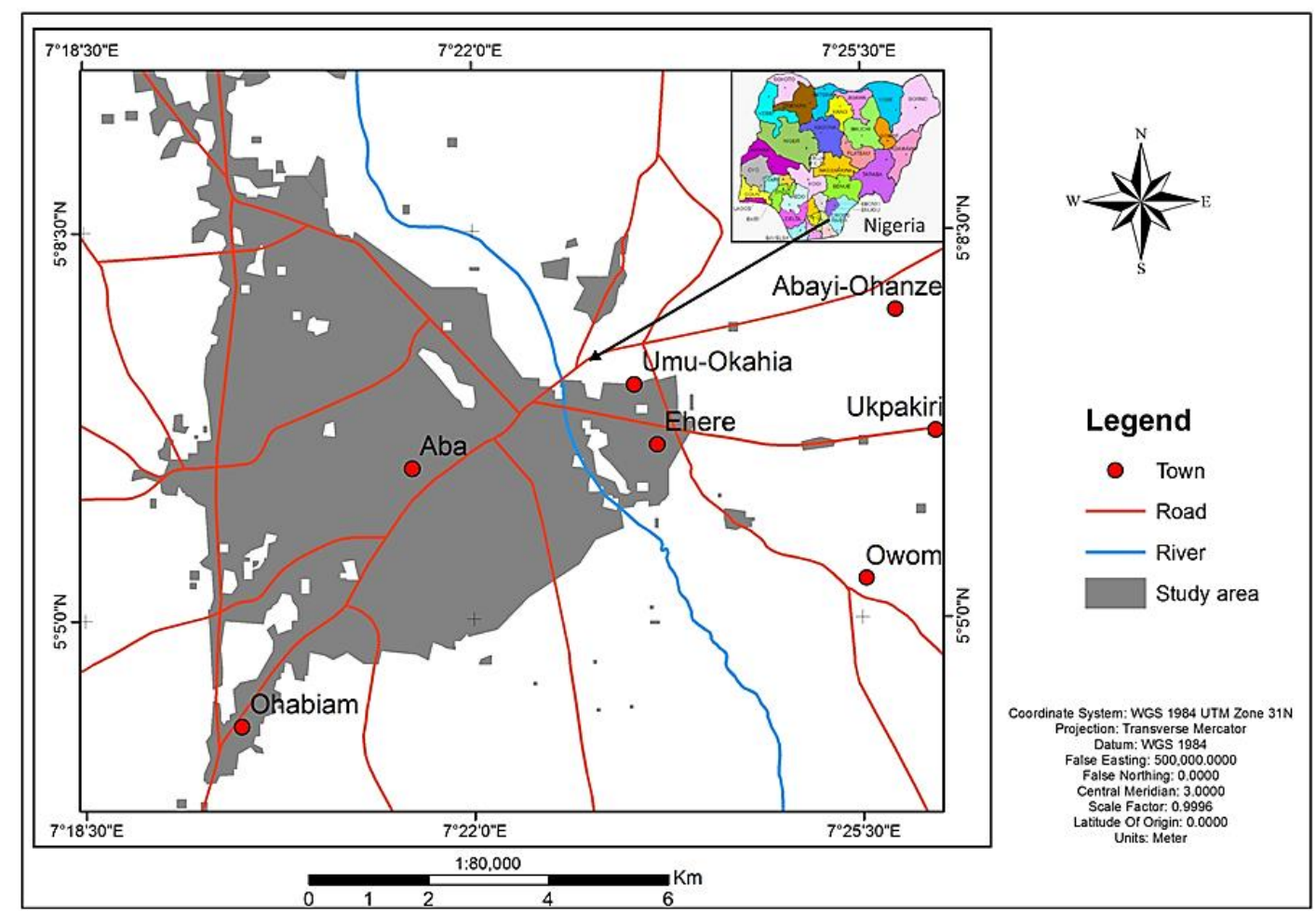

Figure 1. The Study area

The 2014 Population estimate puts Aba at 1,277,300 (Hoiberg, 2010). The study area is surrounded by several oil wells in the neighbouring city of Port-Harcourt, and its major economic contributions are textiles and palm oil (Falola and Heaton, 2008) along with pharmaceuticals, breweries, distilleries, plastics, cement, and cosmetics which made the Ariaria international market to become the largest market in West Africa seconded by the Onitsha main market. In view of the above, Aba city was used in this study as a 'proof of concept' in empirically demonstrating the differences between pixel-based and object-based classification for large scale urban mapping.

\subsection{Data collection, analysis and presentation}

In this paper, we rely mostly on secondary sources of data which include 2012 QuickBird $(0.6 \mathrm{~m})$ satellite image covering Aba main town. Other data and information used for the study were sourced from e-libraries of host publishers, books and other ancillary data. The adopted study workflow is shown in figure 2. The methods of data analysis and presentation are explained below.

\section{a) Image analysis}

For both methods examined in this study, the landcover classes produced were based on 'Anderson's Landuse and landcover scheme of 1976 (Anderson et al., 1976). Figure 3 shows details of the workflow used in the implementation of the empirical work.

i) The pixel-based image analysis (PIXBIA) method was actualised using the semi-automatic supervised classification approach. The process generally involved a training site selection over region/area of interest (R/AOI) based on inherent knowledge of landuse/cover and ground truth (Verhulp and Niekerk, 2017). The systematic-random sampling technique was used in obtaining the training data (Jensen and Gorte, 2001; Matinfar et al., 2007). The study area was divided into four 
(4) quadrants and in every quadrant; at least ten (10) samples each were collected for every landcover class. The randomly collected samples were used to train the computer (semi-automatic) and prescribe the different landuse/cover classes to be classified.

Using ENVI 4.8 software, the maximum likelihood classifier (MLC) which is based on a normalized (gausian) estimate of the probability density function of each class was used because according to Roostaei et al. (2012), MLC has a major advantage over other classifiers. Thus, based on the Bayesian probability theory:

"an unknowm pixel $\mathrm{X}$ with multispectral values ( $\mathrm{n}$ bands) is classified into the class (k) that has the maximum likelyhood $(\max \operatorname{Lk}(\mathrm{x}))^{\prime}$ ". The likelihood function is given on the assumption that the ground truth data of class $k$ will form the gausian (normal) distribution as denoted in equation 1 (Roostaei et al., 2012):

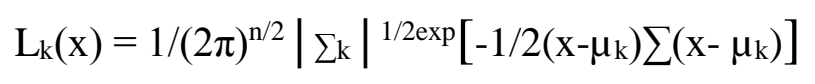

Where $\mu_{\mathrm{k}}$ : mean vector of the ground truth data class $\mathrm{k} \sum \mathrm{k}$ : variance- covariance matrix of $\mathrm{k}$ class produced from the ground data and $|\Sigma \mathrm{k}|$ is the determinant of $\Sigma \mathrm{k}$.

Though robust and simple, sufficient sample data are required for the MLC algorithm to give best result hence the ten training samples collected from each quadrant in the study area.

ii) The Geo-object-based image analysis (GEOBIA) method was actualized based on image segmentation following rule set (brightness/colour and shape) and scale levels and, finally merging similar objects. Classification into information classes were performed using the fuzzy and Nearest Neighbour Classifier methods (Table 1). 


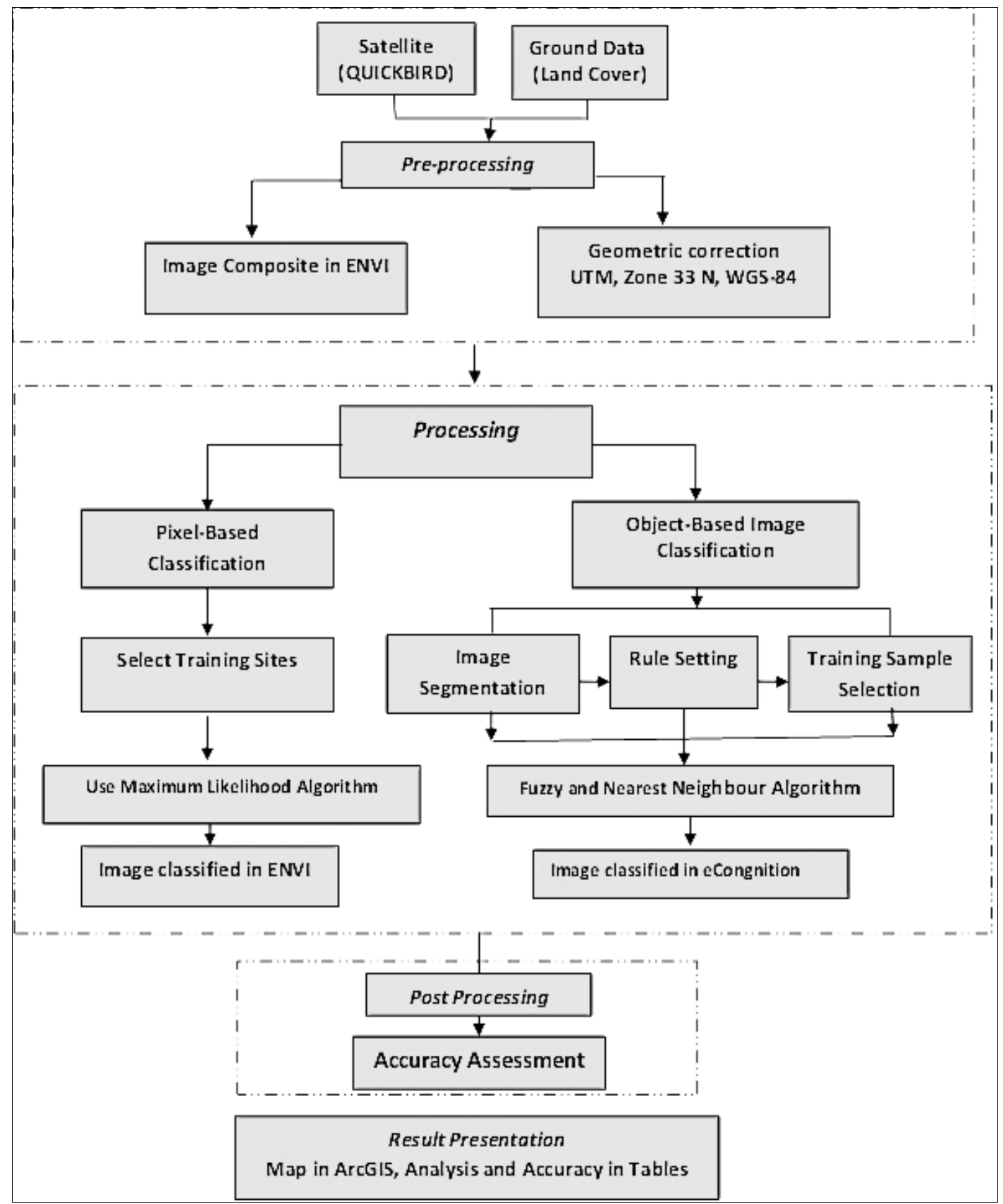

Figure 2. Empirical study workflow

The object-based classification was executed using Definiens (or eCongnition) software after merging and tidying objects into information classes based on set rule for each level of land cover as follows:

Level- $\mathbf{1}$ set rules is as follows:

- Builtup: unclassified with brightness $=>120$, unclassified with rectangular fit $=>0.6$ and $<=0.8$;

- Bareland: unclassified with brightness $=>120$ and $<=140$;

- Forest: unclassified with Red-band $=>70$ and $<=90$;

- Agriculture: unclassified with Red-band =>90 and $<=100$; 
Level- 2 set rules is follows:

- Water: Nearest Neighbour Classifier

\section{b) Accuracy assessment: Overall Accuracy and Kappa Coefficient Statistical Analysis}

Evaluating classification results is an important process in classification procedure ((Lu and Weng, 2007) because classification is incomplete without accessing its accuracy (Matinfar et al., 2007). Confusion Matrix (error matrix) and Kappa Coefficient are both Post Classification (PC) methods for respectively evaluating classification accuracies and comparing classifications agreement to geographic reality (Congalton and Green, 1999; Lu and Weng, 2007; Roostaei et al., 2012). The error matrix (in contingency table) shows the producer (error of omission), user (error of commission) and overall accuracies of classification in percentages (Jensen, 1996). Thus, the higher the accuracy percentage the better. Similarly, the Kappa $(\mathrm{K})$ statistical analysis is 'a discrete multivariate technique used in accuracy assessment' (Congalton and Mead, 1983). Kappa (K) assessment shows the strength of classifications agreement arising from the classification accuracies. The results ranges from $0-1$; where ' 0 ' means no agreement and ' 1 ', a perfect agreement (Altman, 1991; Warrens, 2010).

i) The Overall Accuracy (OA) equation (Matinfar et al., 2007) is given as :

$$
\mathrm{OA}=\frac{\sum_{i=1}^{c} \text { Eii }}{\mathrm{N}}
$$

Where $c$ is the number of classes, $\mathrm{N}$ is the number of certain classes; Eii is the error matrix diagonal cell.

Producer and user accuracies are the mean accuracy value of all classes respectively examined.

ii) Object-based Segmentation Accuracy formula for the segmentation (i.e. the upper bound on classification accuracy), denoted as $\mathrm{A}(\mathrm{U} \lambda)$, is calculated using equation 3 (Liu and Xia, 2010):

$$
A(U \lambda)=\sum_{i=1}^{N} \max (m i, j) / \sum_{i=1}^{N} n i
$$

Where $\boldsymbol{U}$ denotes the segmentation unit; $\boldsymbol{\lambda}$ denotes the scale parameter at which the segmentation unit is generated; mi,j denotes the number of pixels belonging to the class $j$ in the $i$-th image object; and $n i$ denotes the number of pixels in the $i$-th image object (Liu and Xia, 2010).

iii) The Kappa (K) statistical analysis equation (Congalton and Green, 1999; Lu and Weng, 2007; Roostaei et al., 2012) is given as:

$$
\mathrm{K}=\frac{\mathrm{N} \sum_{i=1}^{k} \mathrm{nii}-\sum_{i=1}^{k} \mathrm{ni}+\mathrm{n}+1}{\mathrm{~N}^{2}-\sum_{i=1}^{k} \mathrm{ni}+\mathrm{n}+1}
$$

Where nii is the number of observations in $\mathbf{i}_{\text {th }}$ row and $\mathbf{i}_{\text {th }}$ column on the main matrix diagonal, $\mathbf{n}+\mathbf{1}$ is the total number of observations in $\mathbf{i}_{\text {th }}$ row and $\mathbf{i}_{\text {th }}$ column and $\mathrm{N}$ is the total observations. 


\section{c) Data presentation and interpretation}

The cartographic map embellishments were carried out using ArGIS 10.1 software. Map making was based on conventional cartographic symbols and visual variables such as colour or hue, texture, shape or form, size, pattern, etc. (see Bertin, 1983: Myint et al., 2011). This was aimed at communicating effectively and efficiently to users (Kraak and Ormeling, 2010); most of whom may not be specialist in geoinformation or allied disciplines (see ITC, 2010: 343). With reference to the 1976 Anderson LULC Classification Scheme (Anderson et al., 1976), five landcover classes of (i) Builtup (red), (ii) Bareland (brown), (iii) Thick vegetation or forest (forest green), (iv) Light vegetation or Agric (light green) and (v) Water (blue) were visualized appropriately. The accuracy assessment of both classification methods were presented in Contingency table as percentages (\%) while the Kappa Coefficient result ranges between 0 and 1. The closer the Kappa value is to 1, the higher and better the level of classification agreement to reality, and vice versa (Altman, 1991).

\section{Results and Discussion}

\subsection{Pixel-based and object-based classification assessment}

Table 1, Figures 3a, b and 4 results show that in the pixel-based classification findings, the Bareland (including earth roads) and Builtup (including tar-roads) were aggregated as a result of their similarity in reflectance values thus not very effective in separating urban landcover classes when using high resolution images. Conversely, these same features were well distinguished in the objectbased approach. The bare-land (especially the Golf Course under preparation when the image was captured by the sensor) is well classified and visualised using GEOBIA than in the PIXBIA result (Figure 3). These findings are similar to those of Myint et al. (2011).

Table 1: Percentage Composition and Differences in Landcover Classes

\begin{tabular}{llccccc}
\hline & LULC Type & $\begin{array}{c}\text { Pixel } \\
\text { (No. of pixel) }\end{array}$ & $\begin{array}{c}\text { Object } \\
\text { (No. of pixel) }\end{array}$ & $\begin{array}{c}\text { Pixel } \\
\text { Distribution (\%) }\end{array}$ & $\begin{array}{c}\text { Object } \\
\text { Distribution (\%) }\end{array}$ & $\begin{array}{c}\text { Differences: Pixel } \\
\text { to Object (\%) }\end{array}$ \\
\hline 1. & Builtup & 20252935 & 25099242 & 54.5 & 48 & -6.5 \\
2. & $\begin{array}{l}\text { Forest (Thick } \\
\text { Vegetation) }\end{array}$ & 7877365 & 14622829 & 21.2 & 28 & +6.8 \\
3. & $\begin{array}{l}\text { Bare-land } \\
\text { 4. }\end{array}$ & 7350012 & 3182542 & 10.0 & 6.1 & -3.9 \\
& Water & 10388 & 364686 & 0.1 & 0.7 & +0.6 \\
5. & $\begin{array}{l}\text { Agriculture } \\
\text { (Cultivation) }\end{array}$ & 5285276 & 9057575 & 14.2 & 17 & +2.8 \\
\hline & TOTAL & $\mathbf{5 2 3 2 6 8 7 4}$ & $\mathbf{5 2 3 2 6 8 7 4}$ & $\mathbf{1 0 0}$ & $\mathbf{1 0 0}$ & \\
\hline
\end{tabular}

In addition, Water, thick and light vegetation covers are also well captured and visualized in the object-based approach as evidenced in the tree canopy shape zoomed at scale 1:500 within the golf course under construction when the image was captured in 2012 (Figure 3b). The high class separability in the object-based approach is because the classification of an object into a given landcover class is based on segmentation (shape/colour) and eventual clustering of end member pixel based on fuzzy theory ( 0 or 1$)$ and the nearest neighbour principle likened to the 
regionalisation and proximity concept credited to Vidal de la Blache (1845-1918). Hence, a feature which forms a contiguous shape of interest is classified into one information class based on the established threshold in spectral differences.

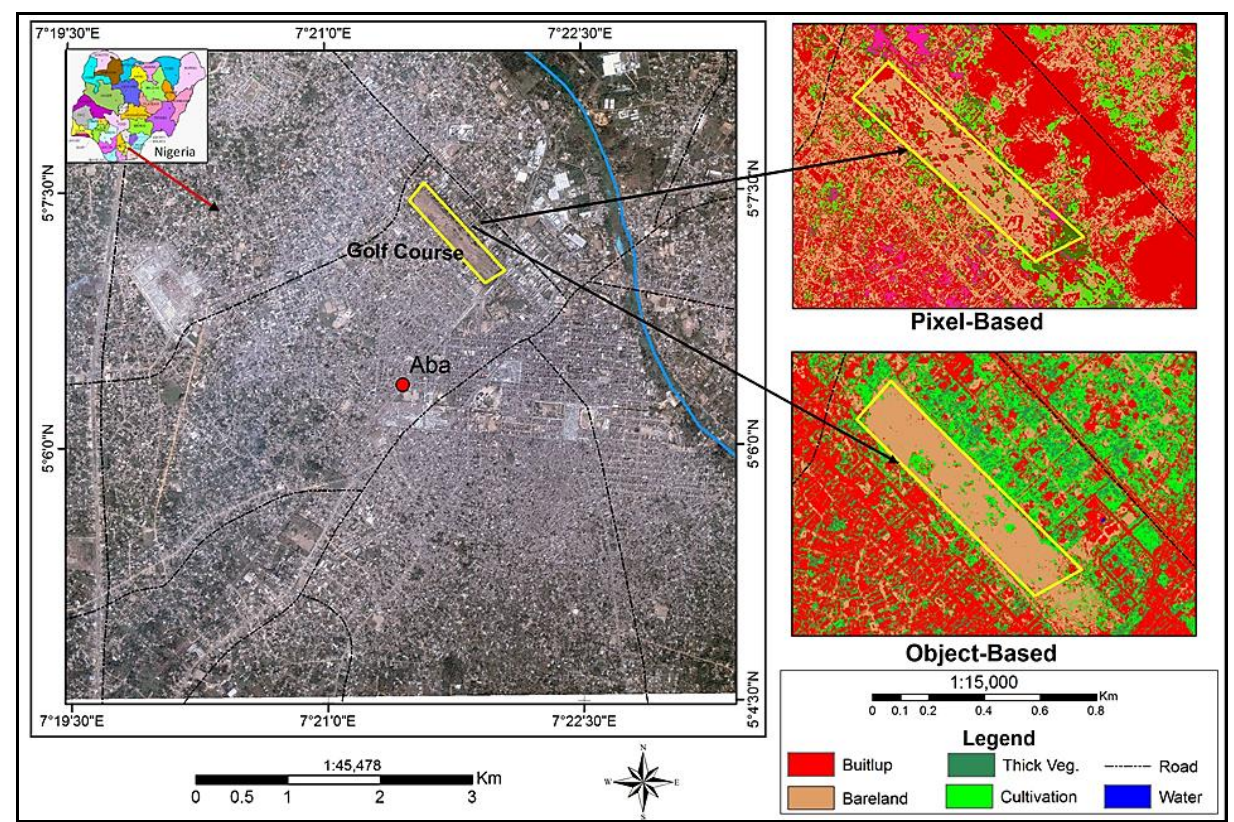

Figure 3a: LULC of Aba: pixel-based method (upper right), object-based method (lower right)

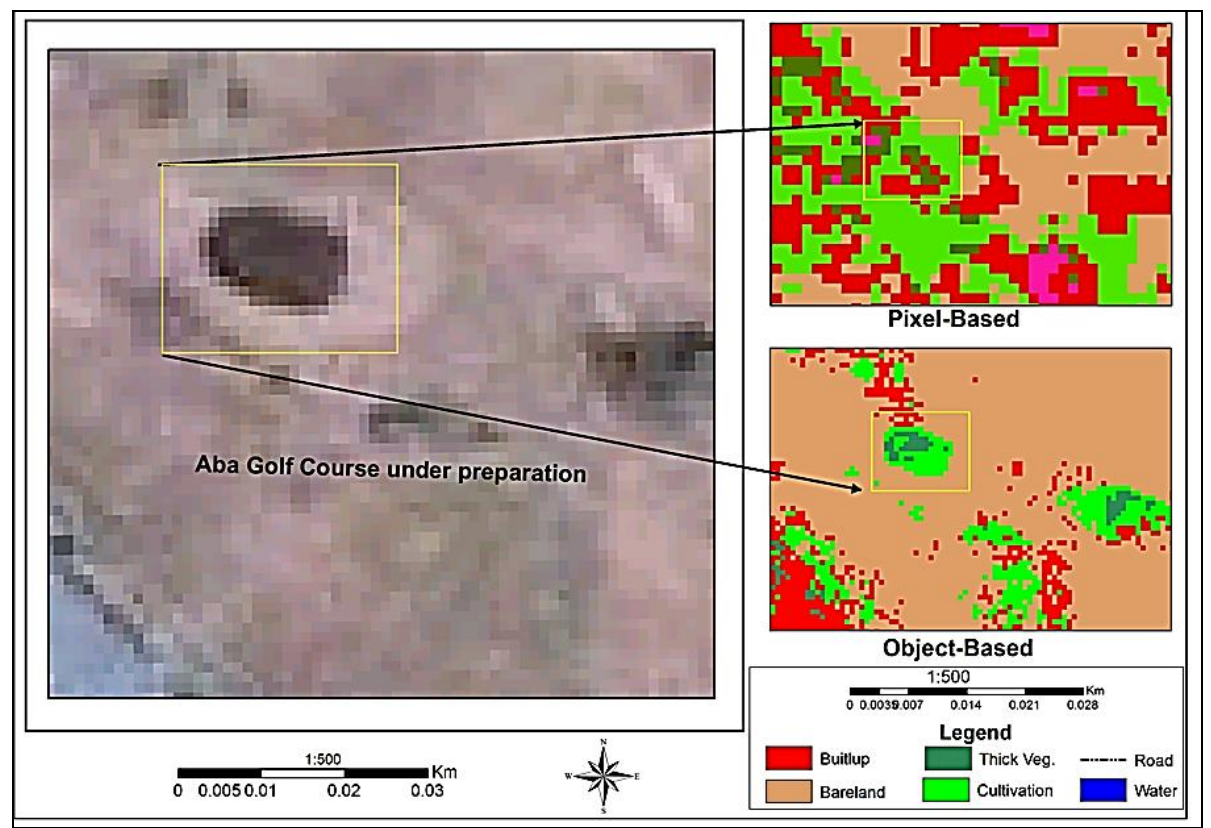

Figure 3b: Scale 1:500 Zoom of pixel-based (upper right) and object-based (lower right) classifications of tree canopy within the cleared golf course within Aba City

Figures $3 \mathrm{a}$ and 4 (right) shows that bare-land, water and light vegetation covers were better classified in the object-based approach. The above findings suggest that the object-based analysis had greater potential for extracting landcover classes from high resolution satellite images than the pixel-based as corroborated in a similar study conducted in northern Australia by Whiteside and Ahmad (2005). 


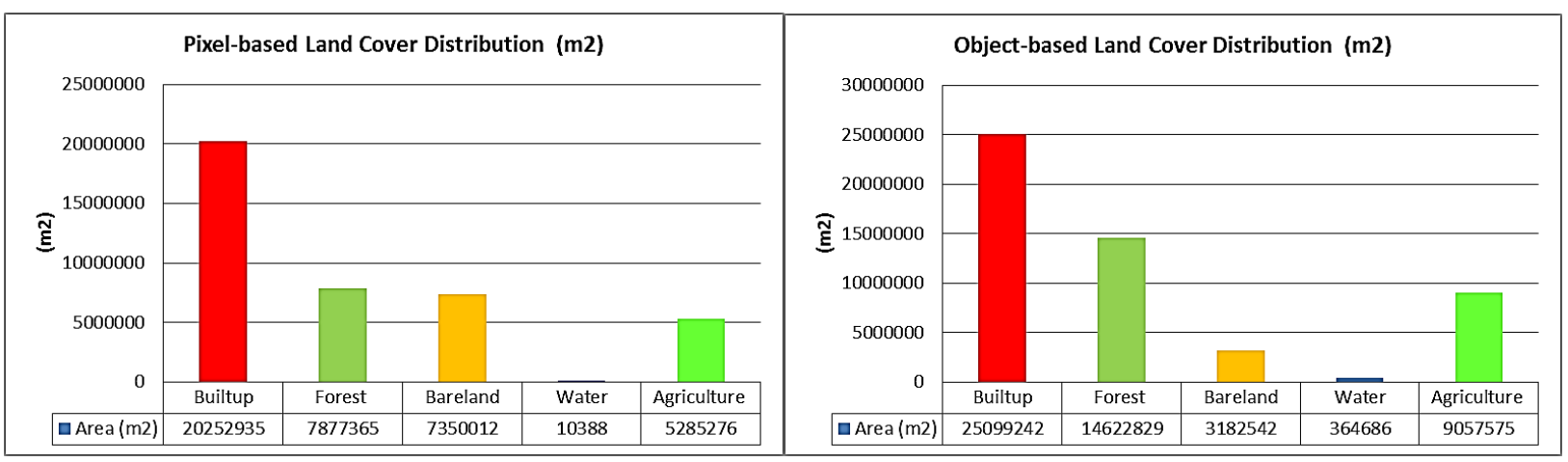

Figure 4: Land cover Composition - (left) pixel-based, (right) object-based

\subsection{Accuracy assessment of PIXBIA and GEOBIA classification results}

Tables 2 and 3 respectively show that the object-based approach offers the best overall accuracy of $98.75 \%$ as against the $79.44 \%$ of the pixel-based. Similarly, the object-based approach gave a better reliable producer accuracy $(\mathrm{PA}=98.42 \%)$ and user accuracy $(\mathrm{UA}=96.70 \%)$ than the pixel-based of $\mathrm{PA}=85.37 \%$ and $\mathrm{UA}=81.04 \%$ respectively.

Table 2: Pixel-based - Confusion matrix showing classification accuracy assessment

\begin{tabular}{llllllll}
\hline Classes & Builtup & Thick Veg. & Bareland & Water & Agric. & Total & UA \\
\hline Builtup & $\mathbf{8 1 4 4 0}$ & 883 & 409 & 0 & 416 & $\mathbf{8 3 1 4 8}$ & $\mathbf{9 7 . 9 5}$ \\
Thick Veg. & 7765 & $\mathbf{1 2 9 2 6}$ & 0 & 0 & 642 & $\mathbf{2 1 3 3 3}$ & $\mathbf{6 0 . 5 9}$ \\
Bareland & 11106 & 1 & $\mathbf{8 8 6 5}$ & 0 & 18 & $\mathbf{1 9 9 9 0}$ & $\mathbf{4 4 . 4 5}$ \\
Water & 0 & 0 & 0 & $\mathbf{3 7 3 9}$ & 0 & $\mathbf{3 7 3 9}$ & $\mathbf{1 0 0}$ \\
Agric. & 3547 & 4532 & 0 & 0 & $\mathbf{6 3 0 8}$ & $\mathbf{1 4 3 8 7}$ & $\mathbf{4 3 . 8}$ \\
\hline Total & $\mathbf{1 0 3 8 5 8}$ & $\mathbf{1 8 3 4 2}$ & $\mathbf{9 2 7 4}$ & $\mathbf{3 7 3 9}$ & $\mathbf{7 6 8 4}$ & $\mathbf{1 4 2 5 9 7}$ & $\boldsymbol{U A}=\mathbf{8 1 . 0 4}$ \\
PA & $\mathbf{7 8 . 4 1}$ & $\mathbf{7 0 . 7 4}$ & $\mathbf{9 5 . 5 9}$ & $\mathbf{1 0 0}$ & $\mathbf{8 2 . 0 9}$ & PA=85.37 & $\boldsymbol{O A}=\mathbf{7 9 . 4 4}$ \\
\hline
\end{tabular}

Kappa Coefficient $(\mathbf{K})=0.62$

Table 3: Object-based - Confusion matrix showing classification accuracy assessment

\begin{tabular}{llllllll}
\hline Classes & Builtup & Thick Veg. & Bareland & Water & Agric. & Total & UA \\
\hline Builtup & $\mathbf{1 0 3 0 4 0}$ & 0 & 0 & 0 & 0 & $\mathbf{1 0 3 0 4 0}$ & $\mathbf{1 0 0}$ \\
Thick Veg. & 304 & $\mathbf{1 4 6 0 1}$ & 0 & 0 & 150 & $\mathbf{1 5 0 5 5}$ & $\mathbf{9 6 . 9 8}$ \\
Bareland & 0 & 0 & $\mathbf{1 0 3 2 1}$ & 0 & 0 & $\mathbf{1 0 3 2 1}$ & $\mathbf{1 0 0}$ \\
Water & 0 & 0 & 0 & $\mathbf{3 8 2 1}$ & 0 & $\mathbf{3 8 2 1}$ & $\mathbf{1 0 0}$ \\
Agric. & 496 & 833 & 0 & 0 & $\mathbf{8 5 3 4}$ & $\mathbf{9 8 6 3}$ & $\mathbf{8 6 . 5 3}$ \\
\hline Total & 103840 & 15434 & 10321 & 3821 & 8684 & $\mathbf{1 4 2 1 0 0}$ & $\boldsymbol{U A}=\mathbf{9 6 . 7 0}$ \\
PA & $\mathbf{9 9 . 2 3}$ & $\mathbf{9 4 . 6 0}$ & $\mathbf{1 0 0}$ & $\mathbf{1 0 0}$ & $\mathbf{9 8 . 2 7}$ & $\mathbf{P A = 9 8 . 4 2}$ & $\boldsymbol{O A}=\mathbf{9 8 . 7 5}$ \\
\hline
\end{tabular}

Kappa Coefficient $(\mathbf{K})=0.97$

In specific, Bare-land (44.45\%) and Light Vegetation (43.8\%) had very low user accuracies in the pixel-based approach. Result of Kappa Coefficient level of classification agreement to geographic reality shows that the object-based approach had a 'very good' agreement of $K=0.97$ while the pixel-based had a 'good' agreement of $\mathrm{K}=0.62$. The findings above suggest that the object-based approach is better relied on than the pixel-based (Warrens, 2010) especially when dealing with large scale mapping using a high resolution satellite image such as QuickBird. The lower Kappa value of $\mathrm{K}=0.62$ for the pixel-based is partly due to the associated mixed classification (MIXELS) resulting 
from contiguous area of divergent DN values. The study shows that the Object-based, is therefore, a better 'soft-landing' when carrying out rapid urban mapping.

\subsection{Implication of findings}

The findings in this paper further corroborate previous studies (Whiteside and Ahmad, 2005). It also further reaffirms that the main advantage of GEOBIA classification over the PIXBIA is that the basic processing units are image objects or segments (aggregates of pixels) which represents real world feature. In addition, object-based approach is a good alternative to traditional pixel based method because it is able to overcome the low resolution problem of salt-and-pepper effect which invariably reduces the local spectral variation caused by crown textures, gaps, and shadows (Yu et al., 2006). Furthermore, the objects in object-based approach as observed from figure $3 \mathrm{~b}$ are spectrally more homogeneous with distinct boundaries (of spatial contiguity), compactness and representative within individual regions than between their neighbours as observed in the pixelbased result. In other words, it has extended mapping capabilities by incorporating, within the traditional spectral mix input, the spatial and textural attributes of homogenous sets of pixel which are spatially auto-correlated from which individual objects are derived (Flores et al., 2009). For in instance, in high spatial resolution imagery, a group of pixels can represent the characteristics of land-cover targets better than single pixel; so, groups of adjacent pixels are organized into objects and each treated as part of a minimum classification unit (Yu et al., 2006).

It is further re-emphasized that the object-based method also has superior performance in classifying vegetation and water areas with a high capability in separating roads and barren (bareland) from builtup (Roostaei et al., 2012). The ancillary data such as the vector layers utilised within object-based classification is advantageous in improving the classification process (Whiteside and Ahmad, 2005) as shown in Figure 3a true colour band composition of satellite image of part of Aba city. Another advantage of object-based method in large scale mapping is that a thematic output composed of geographical entities labelled with land cover classes can be directly sorted into GIS databases, creating or updating usable geoinformation (Hay and Gastila, 2006). Though best for high resolution data, it is informative to also stress that GEOBIA higher accuracies are also guaranteed when compared to the PIXBIA classification approach.

It is instructive to add here that the object-based method equally has its limitations such as oversegmentation or under-segmentation which invariably affect classification accuracy (Liu and Xia, 2010). This may arise from small gaps between discontinuous edges which allow merging of dissimilar regions (Kermad and Chehdi, 2002). It may also cluster dissimilar contiguous pixel which represents a completely different land cover feature. For instance, the edge-based segmentation in object-based approach has not been very successful because of its poor performance in the detection of textured objects (Kermad and Chehdi, 2002). This study has further shown that appreciable reconnaissance knowledge of the study area through field check is a necessity for improved classification and reliable result. 


\section{Summary and Conclusion}

This study examined the concept of Remote Sensing, pixel-based image analysis (PIXBIA) and Geo-object-based image analysis (GEOBIA) classification methods and large scale mapping. It consequently reviewed the role of Remote Sensing in geospatial data provision in geographic studies. It further highlighted the prevailing conditions of mapping from the conventional approach (i.e., land surveying, photogrammetry, etc.) to satellite Remote Sensing. In particular, the study acknowledged that as a result of the rigour in dataset collection, huge financial cost involved, time taken to process them, and envisaged higher accuracy requirements in analysing and mapping geographic data, there is the need to choose wisely the best approach in timely delivering highly accurate information in a manner that they can be readily used for decision making with less errors. Using 2012 Quickbird satellite image covering Aba city in South-eastern Nigeria for an empirical study, the paper examined the pixel-based and object-based methods of classification. The study further assessed the classification accuracies (error matrix) for both classification methods and also tests the level of accuracy agreement to geographic reality using Kappa Coefficient statistical analysis.

The study shows that the object-based approach provides a higher overall accuracy (OA) of $98.75 \%$ than the pixel-based approach (79.44\%). In addition, the object-based approach also gave a better producer accuracy $(\mathrm{PA}=98.42 \%>\mathrm{PA}=85.37)$ and user accuracy $(\mathrm{UA}=96.70>\mathrm{UA}=81.04 \%)$ respectively. With a Kappa Coefficient of $\mathrm{K}=0.97$ (very good) for object-based approach and $\mathrm{K}=0.62$ (good) for pixel-based, the object-based approach proved to be better for separating tree canopies from bare-land especially when carrying out rapid large scale mapping. This include cadastral or property map as obtains in the lands, urban planning and surveys departments in Nigeria (Ufuah, 2003). The higher accuracy of object-based approach over the pixel-based corroborates similar studies conducted in Northern Australia by Whiteside and Ahmad (2005) and Myinth et al. (2011). In view of the above findings, the object-based classification of high resolution images is recommended for rapid large scale mapping especially when funding is limited for flying airplane for the production of orthophotos.

\section{Acknowledgements}

The authors express deep appreciation to all those who contributed in one way or the other to the development and refinement of this paper. The unanimous reviewers are gratefully acknowledged.

\section{REFERENCES}

Akinbode, A 1996, Research Methods in Geography. Ekpoma: Edo State University Publishing House.

Alpha, TR \& Winter, RE 1971, 'Quantitative physiographic method of landform portrayal'. Canadian Cartographer, vol. 8, no. 2, pp. 126-136. http://dx.doi.org/10.3138/374X-71K6-171T-W54R

Altman, DG 1991, Practical Statistics for Medical Research. London, England: Chapman and Hall 
Anderson, JR, Hardy, EE, Roach, JT \& Witmer, RE 1976, A Land Use and Land Cover Classification System for Use with Remote Sensor Data. USGS Professional Paper 964. A revision of the land use classification system as presented in the USGS Circular 671.

Baatz, M, Benz, U, Dehghani, S, Heynen, M, Höltje, A, Hofmann, P, Lingenfelder, I, Mimler, M, Sohlbach, M, Weber, M \& Willhauck, G 2004, eCognition Professional: User guide 4; Munich: Definiens-Imaging.

Bello, IE \& Ojigi, LM 2013, 'Collaborative web mapping and volunteered geographic information: a study in Nigeria'. Applied GIS, vol. 9, no. 2, pp. 1-17. (Online): http://arrow.monash.edu.au/vital/access/manager/Repository/monash:120577

Benz, U, Hofmann, P, Willhauck, G, Lingenfelder, I \& Heynen, M 2004, 'Multi-resolution, Object-oriented fuzzy analysis of Remote Sensing data for GIS-ready information". ISPRS Journal of Photogrammetry and Remote Sensing, Vol. 58, pp. 239-258.

Bertin, J 1983, Semiology of graphics. Madison, WI: University of Wisconsin Press.

Chang, K 2012, Introduction to geographic Information systems. (6th Edition). New York (NY): McGrawHill.

Collier, P 2002, 'The Impact on Topographic Mapping of Developments in Land and Air Survey'. Cartography and Geographic Information Science, vol. 29, no. 3, pp. 155-174. http://dx.doi.org/10.1559/152304002782008440

Congalton, R \& Green, K 1999, Assessing the Accuracy of Remotely Sensed Data: Principles and Practices, Boca Raton, Florida, CRC/ Lewis Publishers, 137 p.

Congalton, RG \& Mead, RA 1983, 'A quantitative method to test for consistency and correctness in photo interpretation'. Photogrammetric Engineering and Remote Sensing, vol. 49, pp. 69-74.

Dymond, JR \& Shepherd, JD 1999, Correction of the topographic effect in Remote Sensing. IEEE Transactions on Geoscience and Remote Sensing, vol. 37, pp. 2618-2620.

Fabiyi, OO, Ige-Olumide, O \& Enaruvbe, OG 2012, Spatial analysis of flood plains in Nigeria from SPOT satellite elevation data in: Ayeni, B. and O.O. Faboyi (eds.), Geospatial Technology and Digital Cartography for National Security, Tourism and Disasters Management. Proceedings of Joint Conference of GEOSON and NCA, RECTAS, Ile-Ife, Nigeria. 19 - 22 November. Pp. 239-252

Falola, T \& Heaton, MM 2008, A History of Nigeria. Cambridge, UK: Cambridge University Press. ISBN 978-0-521-68157-5.

Fasona, MJ \& Omojola, AS 2004, GIS and Remote Sensing For Urban Planning: A Case of Festac Town, Lagos Nigeria. In Proceedings of 12th International Conference On Geoinformatics, University of Gavle: Sweeden.

Flores, ES, Caravantes, RD, Javier Chávez, J \& Olivas, AG 2009, GIS Improved object-based Classification for Land Use/Cover Change Detection in a Human Altered Deciduous Forest Environment. ASPRS 2009 Annual Conference, Baltimore, Maryland. March 9-13.

Gao, Y \& Mas, JF 2008, 'A Comparison of the Performance Of pixel-based And object-based Classifications Over Images With Various Spatial Resolutions'. Journal of Earth Sciences, vol. 2, no. 1, pp. 27 -35.

Goodchild, MF 1992, 'Geographic Information Science'. International Journal of Geographical Science, vol. 6, no. 1, pp. 31-45. [online]: from http://www.geog.ucsb.edu/ good/papers/166.pdf. Accessed February 02, 2015.

Goodchild, MF 2009, 'NeoGeography and the nature of geographic expertise'. Journal of Location Based Services, vol. 3, no. 2, pp. 82-96. doi: 10.1080/17489720902950374 
South African Journal of Geomatics, Vol.6, No.3, October 2017

Hay, GJ \& Gastilla, G 2006, 'Object-based image analysis: strength, weakness, opportunities, and threats (SWOT)'. 1st International Conference on object-based Image Analysis (OBIA 2006), 4-5, July, 2006, Salzburg, Austria.

Hay, GJ, Marceau, DJ, Dube, P \& Bouchard, A 2001, 'Multiscale Framework For Landscape Analysis: Object-Specific Analysis And Upscaling’ Landscape Ecology, vol. 16, no. 6, pp. 471-490.

Hoiberg, DH 2010, Aba. Encyclopedia Britannica. I: A-Ak - Bayes (15th ed.). Chicago, IL: Encyclopedia Britannica, Inc. ISBN 978-1-59339-837-8.

Ikhuoria, I \& Ogedegbe, SO 1998, 'Typology, Functions and Production Technology of Cartographic Products in Nigeria'. The Cartographic Journal, vol. 35, no. 1, pp. 49-60.

Ikhuoria, IA 1998, Fundamentals of Remote Sensing, Photo Interpretation and Geographic Information Systems (Monograph), University of Benin, Benin City. St. Ambrose Computer Services 128 p.

Imhof, E 1965, Kartographische Geldndedarstellung. Berlin: Walter de Gruyter. http://dx.doi.org/10.1515/9783110843583

Imhof, E 2007, Cartographic relief presentation. Redlands, Carlifornia: ESRI press. 388p

ITC, 2010, GI, Science and Earth Observation: A processed-based approach. ITC Educational Textbook Series, Faculty of Geoinformation Science and Earth Observation, University of Twente, Enschede, The Netherlands.

Jensen, JR 1996, Introductory Digital Image Processing: A Remote Sensing Perspective (Second edition). Upper Saddle River, New Jersey, USA. Prentice Hall, Inc.

Jensen, LLF \& Gorte, BGH 2001, Principle of Remote Sensing, Chapter 12 Digital image classification, ITC, Enchede, (2nd Edition), The Netherlands.

Kermad, CD \& Chehdi, K 2002, 'Automatic Image Segmentation System through Iterative Edge-Region CoOperation’. Image and Vision Computing, vol. 20, no. 8, pp. 541-555.

Liu, D \& Xia, F 2010, 'Assessing object-based Classification: Advantages and Limitations’. Remote Sensing Letters, vol. 1, no. 4, pp. 187-194, DOI: 10.1080/01431161003743173.

Lu, D \& Weng, Q 2007, 'A Survey of Image Classification Methods And Techniques For Improving Classification Performance', International Journal of Remote Sensing, vol. 28, no. 5, pp. 823-870, DOI: 10.1080/01431160600746456

Matinfar, HR, Sarmadian, F, Alavi-Panah, SK \& Heck, RJ 2007, 'Comparisons of Object-Oriented and pixel-based Classification of Land Use/Land Cover Types Based on Lansadsat7, Etm+ Spectral Bands (Case Study: Arid Region of Iran)'. American-Eurasian J. Agric. \& Environ. Sci., vol. 2, no. 4, pp. 448456.

McRoberts, RE \& Tomppo, EO 2007, 'Remote Sensing Support for National Forest Inventories', Remote Sensing of Environment, vol. 110, pp. 412-419.

Myint, SW, Gober P, Brazel, A, Grossman-Clarke, S \& Weng, Q 2011, 'Per-pixel vs. object-based Classification of Urban Land Cover Extraction Using Spatial Resolution Imagery'. Remote Sensing of Environment, vol. 115, no. 5, pp. 1145-1161

Nkeki, FN \& Asikhia, MO 2014, 'Mapping and Geovisualizing Topographical Data Using Geographic Information System (GIS)'. Journal of Geography and Geology, vol. 6, no. 1, pp.1-13. 
South African Journal of Geomatics, Vol.6, No.3, October 2017

Ojigi, LM 2006, Analysis of spatial variations of Abuja land use and land cover from image classification algorithms. In Proceedings of the ISPRS Commission VII Mid-term symposium. "Remote Sensing: From Pixels to Processes". Enschede, The Netherlands.

Ojigi, LM 2012, An Evaluation of the Efficiency of the Land Use Act 1978 of the Federal Republic of Nigeria and its Implications in Minna and Environs. FIGWW 2012: Knowing to Manage the Territory - Protect the Environment - Evaluate the Cultural Heritage. TSO1E-: Pro Poor Land Management: Paper No.5577.

Olomo, OR, Ufuah, ME \& Akpan, DV 1998, Appraisal of the Federal Survey Department, Nigeria, in: O.Y. Balogun, and N.O. Uluocha, (Eds.), Cartography and the challenges of the 21st Century in Nigeria, Nigerian Cartographic Association (NCA), Lagos. pp. 7-23.

Omuta, GED 1984, Urbanization and Industrialization: The Case of Benin. In: P.O. Sada, and A.B. Osirike, (Eds.), Case Studies in Migration and Urbanization in Nigeria. Perspectives in Policy Issues. Proceedings of the Policy Seminar in Migration, Urbanization and Living Conditions in Nigerian Cities. The University of Benin on March 5 - 6. Pp. 85 - 97.

Osborne, P (2013), The Mercator projections. Edinburgh. doi:10.5281/zenodo.35392

Ozah, PA \& Kufuniyi, O 2008, 'Accuracy assessment of contour interpolation from 1:50,000 topographical maps and SRTM data for 1:25,000 topographical mapping'. The International Archives of the Photogrammetry, Remote Sensing and Spatial Information Sciences, vol. 37, (B7), pp. 1348-1353.

Rilwani, ML 2014, Remote Sensing and GIS based land suitability Assessment for Crop Production in Nigeria. Ibadan, Ibadan University Press, Supported by TetFund.

Rilwani, ML, Bello, IE \& Onothoja, TU 2015, 'Orchestration of Land Grab in Africa: Implications for Governance and Development in Nigeria'. International Journal of Governance and Development, vol. 4, no. 1, pp. 31-54.

Roostaei, SH, Alavi, SA, Nikjoo, MR \& Valizadeh-Kamran, KH 2012, 'Evaluation of Object-Oriented and pixel-based Classification Methods for Extracting Changes in Urban Area'. International Journal of Geomatics and Geosciences, vol. 2, no. 3, pp. 738-749.

Snyder, JP 1993, Flattening the earth: Two thousand years of map projection. Chicago: library of Congress Cataloging.

Soneye, ASO \& Akintuyi, A 2013, 'A Critical Appraisal of Remote Sensing and Topographical mapping in Nigeria: 1937 - 2010'. Lagos Journal of GIS, vol. 1, no. 2, pp. 16 - 28

Syed, S, Dare, P \& Jones, S 2005, 'Automatic Classification of Land Cover Features With High Resolution Imagery and Lidar Data: An Object Oriented Approach'. Proceedings of SSC2005 Spatial Intelligence, Innovation and Praxis: The national biennial Conference of the Spatial Sciences Institute, September, 2005. Melbourne: Spatial Sciences Institute. ISBN: 0-9581366-2-9. Pp. 512 - 522.

Tobler, W 1970, A Computer Movie Simulating Urban Growth in Detroit Region. Economic Geography, 46(2):234-240.

Ufuah, ME 2003, Non-revision of 1:50,000 topographic maps and its implications for sustainable development in Nigeria. Proceeding of the $21^{\text {st }}$ International Cartographic Association Conference on Cartographic Renaissance. pp. 2579-2589, Durban, South Africa.

Verhulp, J \& Niekerk, AV 2017, 'Transferability of decision trees for land cover classification in a heterogeneous area'. South African Journal of Geomatics, vol. 6, no. 1, pp. 30 - 46. 
Warrens, MJ 2010, 'Inequalities between multi-rater kappas'. Advances in Data Analysis and Classification, vol. 4, pp. 271-286. doi:10.1007/s11634-010-0073-4

Whiteside, T \& Ahmad, W 2005, A comparison of Object-Oriented and pixel-based Classification Methods for Mapping land cover in northern Australia. Proceedings of SSC2005 Spatial intelligence, innovation and praxis: The national biennial Conference of the Spatial Sciences Institute, September 2005. Melbourne: Spatial Sciences Institute. pp. 1225-1231

Worboys, MF 2003, GIS: A Computing perspective. Taylor and Francis, UK.

Yokoyama, R, Shirasawa, M \& Pike, RJ 2002, 'Visualizing Topography By Openness: A New Application Of Image Processing To Digital Elevation Models'. Photogrammetric Engineering and Remote Sensing, vol. 68, no. 3, pp. 257-265.

Yu, Q, Gong, P, Clinton, N, Biging, G, Kelly, M \& Schirokauer, D 2006, 'Object-based Detailed Vegetation Classification with Airborne High Spatial Resolution Remote Sensing Imagery’. Photogrammetric Engineering \& Remote Sensing, vol. 72, no. 7, pp. 799-811. 